\title{
Postoperative morbidity differences between proximal and distal knee saphenous harvesting in coronary artery bypass graft surgery
}

\author{
Ismail Selçuk ${ }^{*}$, Nehir Selçuk², Bülent Barış Güven ${ }^{3}$ \\ ${ }^{1}$ SULTAN 2. ABDULHAMID HAN TRAINING AND RESEARCH HOSPITAL, DEPARTMENT OF CARDIOVASCULAR SURGERY, ISTANBUL, TURKEY \\ ${ }^{2}$ SIYAMI ERSEK THORACIC AND CARDIOVASCULAR SURGERY TRAINING AND RESEARCH HOSPITAL, DEPARTMENT OF CARDIOVASCULAR SURGERY, ISTANBUL, TURKEY \\ ${ }^{3}$ SULTAN 2. ABDULHAMID HAN TRAINING AND RESEARCH HOSPITAL, DEPARTMENT OF ANESTHESIOLOGY AND REANIMATION, ISTANBUL, TURKEY
}

\begin{abstract}
Objectives. Coronary artery bypass grafting (CABG) is the most common procedure in cardiac surgery and the great saphenous vein (GSV) are the preferred conduits. The effects of saphenous vein incision (SVI) harvesting site choice on SVI wound complications, pretibial edema, and the need for compression stockings were evaluated retrospectively in patients undergoing CABG surgery. Materials and Methods. A total of 1900 patients operated for CABG between 2003 and 2021 in our clinic were included in this study, with GSV harvest performed at below-knee level (Group-A, n:841) and above-knee level (Group-B, n:1059). SVI was made $2 \mathrm{~cm}$ superior and $1 \mathrm{~cm}$ anterior to the medial malleolus in group-A; and $3 \mathrm{~cm}$ superior to medial epicondyle, extending to $3 \mathrm{~cm}$ inferior to the inguinal ligament in group-B. Examination for edema was made with 4-5 seconds of thumb pressure at the ankle level, then the depth of the pit was measured. Results. Ankle edema (Group-A n:132, Group-B n:25), the use of compression stockings (Group-A n:97, Group-B n:13), and paresthesia (Group-A n:51, Group-B n:10) were different between the two groups and the differences were statistically significant. However, prolonged wound healing (Group-A n:11, Group-B n:38), superficial wound infection (Group-A n:6, Group-B n:11), hematoma (Group-A n:4, Group-B n:9), and lymphorrhea (Group-A n:4, Group-B n:7) incidences were not statistically different between the two groups. Conclusions. Among patients with GSV extracted using the open conventional surgery technique, pretibial edema, paresthesia, and compression stocking use were observed less frequently in patients with preoperative doppler-ultrasonography evaluation and above-knee saphenous harvest.
\end{abstract}

\author{
Category: Original Research Paper \\ Received: July 12, 2021 \\ Accepted: September 06, 2021 \\ Published: November 15, 2021 \\ Keywords: \\ coronary artery bypass, saphenous vein graft, graft \\ incision, morbidity \\ * Corresponding author: \\ Ismail Selçuk, \\ University of Health Sciences Turkey, Sultan 2 \\ Abdulhamid Han Training and Research Hospital, \\ Department of Cardiovascular Surgery, Istanbul, Turkey, \\ 34668 \\ E-mail: ismailselcuk35@gmail.com
}

\section{Introduction}

The left internal mammary artery (LIMA) and the great saphenous vein (GSV) are the most preferred grafts for coronary artery bypass grafting (CABG) operations [1]. Postoperative donor site morbidity in CABG surgery is strongly associated with the length and location of the incision [2]. The incidence of wound complications (surgical site infection, lymphorrhea, prolonged wound healing, hematoma, serous drainage, edema) at the GSV harvest site is $1-2 \%[3,4]$. Therefore, the course and quality of GSV is evaluated with color doppler ultrasonography (CDU), and various harvesting techniques are performed (endoscopic, minimally invasive or tunneling) in order to prevent postoperative saphenous vein incision (SVI) site complications. However, open surgery still remains the most preferred technique. Injury of the saphenous nerve and ankle edema are common in saphenous extraction close to the ankle because superficial venous flow is impeded. Studies about the association between wound complications and the location of the harvested segment (above or below knee) are deficient. In this study, the effect of incision site on GSV harvest wound complications and patient comfort was investigated retrospectively.

\section{Materials and Methods}

This study was approved by the Institutional Review Board of Haydarpasa Numune Training and Research Hospital (HNEAH-KAEK 2021/146-3374). Patients who underwent CABG surgery in our clinic between January 2003 and January 2021 were reviewed retrospectively. A total number of 2139 patients with scheduled isolated CABG surgery were included. Patients were grouped according to the location of SVI as Group A (below-knee, 
n=841) and Group B (above-knee $n=1059)$. Patients who received unilateral GSV grafts in both groups were included in the study. In Group B, GSVs with a diameter of $<5 \mathrm{~mm}$ were used as grafts in RDUS measurements, and a below-knee GSV graft was used in patients with a diameter of $>5 \mathrm{~mm}$. Locations of SVI were determined according to the operating surgeon's preference. All of the surgeries were performed by the same team, with the same senior surgeon. No criterion was used for the choice of the harvest site. Patients with peripheral vascular disease, BMI $\geq 30 \mathrm{~kg} / \mathrm{m} 2$, edema secondary to another pre-existing disease (cardiac, hepatic, renal, thyroid), lacking medical records, fibrotic GSV on RDUS examination, bilateral GVS grafts used and GSV removed endoscopically were excluded. Demographic data including age, sex, body mass index (BMI), tobacco use, and presence of comorbidities were obtained from the database of the institution and are illustrated in Table 1. The course of GSV was detected with ultrasonography and marked on the skin with a permanent marker before surgery. All the patients were medicated in the operating room with prophylactic intravenous (IV) $1 \mathrm{~g}$ cefazolin sodium. IV clindamycin was used if patient was allergic to penicillin.

Table 1. Demographic data for the studied population

\begin{tabular}{|l|c|c|c|c|}
\hline \multicolumn{2}{|c|}{} & $\begin{array}{c}\text { Below-knee } \\
(\mathbf{n = 8 4 1})\end{array}$ & $\begin{array}{c}\text { Above-knee } \\
(\mathbf{n = 1 0 5 9 )}\end{array}$ & P \\
\hline \multirow{2}{*}{ Gender } & Female & $244(29.3 \%)$ & $339(32.2 \%)$ & 0,159 \\
\hline Age & $597(70.7 \%)$ & $720(67.8 \%)$ & \\
\hline PAD & $66,7 \pm 5,29$ & $67.69 \pm 5.46$ & 0.88 \\
\hline HT & $118(14 \%)$ & $139(13 \%)$ & 0.018 \\
\hline DM & $218(26 \%)$ & $286(27.1 \%)$ & 0.595 \\
\hline COPD & $185(22 \%)$ & $190(18 \%)$ & 0.027 \\
\hline SMOKING & $93(11 \%)$ & $159(15 \%)$ & 0.012 \\
\hline CRF & $168(20 \%)$ & $232(22 \%)$ & 0.305 \\
\hline BMI & $42(5 \%)$ & $64(6 \%)$ & 0.322 \\
\hline
\end{tabular}

PAD: Peripheral artery disease, HT: Hypertension, DM: Diabetes Mellitus, COPD: Chronic Obstructive Pulmonary Disease, CRF: Chronic Renal Failure, BMI: Body Mass Index

Wound site complications (surgical site infection, lymphorrhea, prolonged wound healing, hematoma, paresthesia), pretibial edema, and long-term (1 month after the discharge) need for compression stockings (15-18 $\mathrm{mmHg}$ ) were investigated during postoperative follow up.

\section{Surgical Technique}

CABG operations were performed under general anesthesia with cardiopulmonary bypass. SVI for the Group A patients was performed $2 \mathrm{~cm}$ superior and $1 \mathrm{~cm}$ anterior to the medial malleolus, and incision was extended up to the inguinal area, if needed. SVI for the Group B patients was performed between $3 \mathrm{~cm}$ superior to medial epicondyle, and $3 \mathrm{~cm}$ inferior to the inguinal ligament. After extraction, bleeding control was achieved and hemovac drain was inserted. Subcutaneous tissue and skin were closed with Vicryl sutures. Wound dressings were placed, then the leg was wrapped with elastic bandage. Perioperative antibiotic prophylaxis was repeated every 90 minutes during surgery. Postoperative prophylaxis was given every 8 hours in the first 24 hours.

\section{Examination of edema}

Examination of pretibial edema was performed by measuring the depth of the pit created by pressing the thumb on the skin of the ankle. Edema was classified as; $1+\leq 2 \mathrm{~mm}, 2+: 2-4 \mathrm{~mm}, 3+:$ 4-6 mm, and 4+: 6-8 mm, according to the depth measured. Routine examination for edema and measurement of the perimeter of the ankle was performed in both groups daily until discharge, then during every follow-up appointment.

\section{Results}

A total of 1900 patients were included in the study, with 841 in Group A (below-knee) and 1059 in Group B (aboveknee). 239 patients were excluded in the study (Figure 1). At the saphenous harvest location, paresthesia was observed in 61 patients, prolonged wound healing in 49 patients, superficial wound infection in 17 patients, lymphorrhea in 11 patients, and hematoma in 13 patients (Table 2). In 157 patients, ankle edema was detected, and 110 patients needed compression stockings (Table 3 ).

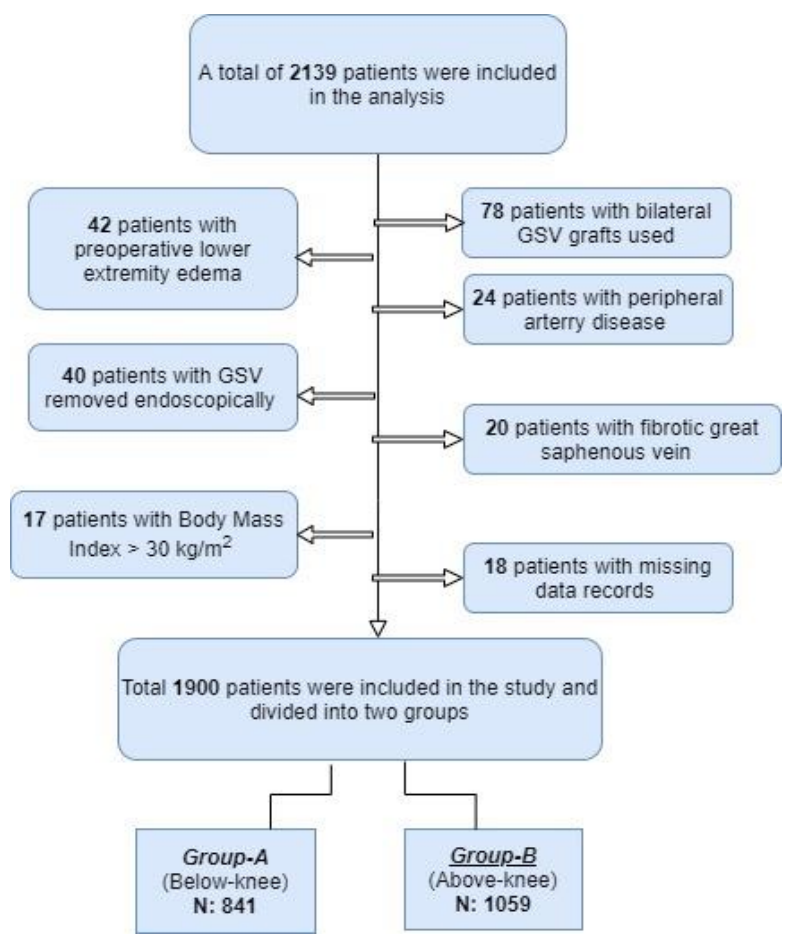

Figure 1. Flow chart for the retrospective study (GSV: Great saphenous vein) 
Table 2. Postoperative complications

\begin{tabular}{|l|c|c|c|}
\hline & $\begin{array}{c}\text { Group-A } \\
(\mathbf{n : 8 4 1})\end{array}$ & $\begin{array}{c}\text { Group-B } \\
(\mathbf{n : 1 0 5 9 )}\end{array}$ & $\mathbf{P}$ \\
\hline Lymphorrhea & 4 & 7 & 0.597 \\
\hline Cellulite & 6 & 11 & 0.455 \\
\hline Hematoma & 4 & 9 & 0.363 \\
\hline $\begin{array}{l}\text { Prolonged } \\
\text { wound healing }\end{array}$ & 18 & 31 & 0.282 \\
\hline Paresthesia & 51 & 10 & 0.0001 \\
\hline Edema & 132 & 25 & 0.0001 \\
\hline
\end{tabular}

Table 3. Edema classification and use of compression stockings

\begin{tabular}{|l|c|c|c|}
\hline & $\begin{array}{c}\text { Group-A } \\
\text { (n:841) }\end{array}$ & $\begin{array}{c}\text { Group-B } \\
\text { (n:1059) }\end{array}$ & P \\
\hline 1+ edema & 28 & 17 & \\
\hline 2+ edema & 72 & 8 & 0.0001 \\
\hline 3+ edema & 32 & - & \\
\hline 4+ edema & - & - & 0.0001 \\
\hline $\begin{array}{l}\text { Use of } \\
\text { compression } \\
\text { stockings }\end{array}$ & 97 & 13 & 0 \\
\hline
\end{tabular}

The difference in the incidence of the ankle edema (Group A: 132, Group B:25, p<0.05), the need for compression stockings (Group A:97, Group B:13, p<0.05), and postoperative paresthesia (Group A:51, Group B:10, $\mathrm{p}<0.05)$ were statistically significant between the two groups. The difference in prolonged wound healing (Group A:11, Group B:38, p>0.05), superficial wound infection (Group A:6, Group B:11, p>0.05), hematoma (Group A:4, Group B:9, p>0.05), and lymphorrhea (Group A:4, Group $\mathrm{B}: 7, \mathrm{p}>0.05)$ were not statistically significant between the two groups.

There were 25 patients with edema below the knee in Group B. Fourteen among theses had SVI partially extended below-knee because of the preoperative detection with DUS with poor-quality (fibrotic, aneurysmal, history of venous thrombosis) saphenous graft in the contralateral leg.

Treatment methods and comorbidities of the patients with prolonged wound healing are summarized in Table 4. Among the group of patients with prolonged wound healing, 18 patients had peripheral artery disease, 27 patients had diabetes mellitus and 4 patients had Buerger disease. Vacuum-assisted closure (VAC) was used in 22 patients, long-term application of sterile wound dressings being sufficient for 17 patients. Surgical debridement was performed for 10 of the patients; 3 of them were in Group A (2 patients with hematoma, 1 with lymphorrhea) and 7 of them were in Group B (4 patients with hematoma, 3 patients with lymphorrhea)
Patients with wound infection, cellulitis and lymphorrhea were treated with oral antibiotics and regular sterile wound dressing. Patients with hematoma (Group $A=3$, Group $B=7$ ) were treated with drainage, or elastic bandages and topical mucopolysaccharide ointment (445 $\mathrm{mg}=40000 \mathrm{U}$ mucopolysaccharide polysulfate). Compression stockings (medium pressure/ 15-18mm $\mathrm{Hg}$, below knee) were used for patients with pretibial edema during hospital stay. Patients with persistent edema after discharge continued to use medium-pressure below-knee stockings for 4-6 weeks.

Table 4. Comorbidities and treatment methods in patients with prolonged wound healing

\begin{tabular}{|l|c|c|c|}
\hline & $\begin{array}{c}\text { Group A } \\
(\mathbf{n ; 1 8})\end{array}$ & $\begin{array}{c}\text { Group B } \\
(\mathbf{n ; 3 1})\end{array}$ & P \\
\hline PAD & 7 & 11 & 0.346 \\
\hline DM & 10 & 17 & 0.178 \\
\hline $\begin{array}{l}\text { Buerger } \\
\text { Disease }\end{array}$ & 1 & 3 & 0.317 \\
\hline VAC & 8 & 14 & 0.201 \\
\hline LTAWD & 7 & 10 & 0.467 \\
\hline Debridement & 3 & 7 & 0.206 \\
\hline
\end{tabular}

PAD; Peripheral artery disease, DM; Diabetes

Mellitus, VAC; Vacuum-assisted closure, LTAWD:

Long-term application of sterile wound dressings

\section{Discussion}

Coronary artery bypass grafting surgery is the most common cardiac surgery procedure and LIMA and GSV are usually the most preferred grafts [5,6]. Recently, widespread use of multivessel bypass surgery caused the usage of longer saphenous grafts more frequently.

The saphenous wound complications of CABG surgery are responsible for $15 \%$ of the total postoperative morbidity [7,8]. Insufficient mobilization caused by GSV harvest wound complications give rise to pulmonary complications in the short term, and pressure ulcers in the long term; consequently, longer hospital stay and problems with patient psychology may be encountered. Therefore, the GSV should be evaluated by detailed CDU and the correct graft harvesting technique should be determined to reduce SVI complications.

Preoperative ultrasonographic screening of the saphenous vein is beneficial in order to avoid excessive incisions. Temizkan et al. [7] demonstrated fewer postoperative SVI complications in patients evaluated with preoperative ultrasonography. Both groups were evaluated with detailed preoperative CDU in our study. Rates of postoperative wound complications were not statistically different between the two groups. 
Various harvesting techniques are implemented, such as bridging technique, endoscopic vein harvesting $(\mathrm{EVH})$ and open surgery, in order to reduce postoperative morbidity related to the harvesting technique. Incisions are smaller in the bridging technique and EVH leading to less tissue damage and better tissue perfusion and consequently fewer postoperative wound complications. In our clinic, GSV has been removed endoscopically for the last 3 years, but it is not routinely performed due to the high cost. Nevertheless, technical difficulties, poor costeffectiveness, risk of $\mathrm{CO} 2$ embolization, difficulty of the technique, and longer learning curve have led to open surgery still remaining as the most preferred technique $[9,10]$. Open surgery for GSV harvest is also the most commonly chosen technique in our institution.

In general, direction of flow in the perforating veins is from the superficial veins towards the deep veins. However, venous flow below the ankle is from the deep venous arch towards the superficial veins of the foot [7]. Hence, the most distal level of saphenous harvest should be minimum 10 centimeters superior of the medial malleolus in order to avoid the edema of the foot and ankle [11]. The venous return of the foot towards the tibioperoneal deep venous system is therefore preserved [7]. Deep venous insufficiency is the physiopathological mechanism which causes ankle edema, and compression stockings are needed accordingly to treat pretibial edema after GSV extraction. Furthermore, pretibial and infrapatellar branches of the saphenous nerve are more frequently injured because of the close proximity of the saphenous vein and nerve at the below-knee level. Ramasastry et al. [12] demonstrated that patients whose saphenous extractions were performed by an upwards dissection from medial malleolus had a higher incidence of paresthesia. Also in our study, the incidence of ankle edema, compression stocking use, and paresthesia was significantly higher in patients with below-knee GSV harvest.

The most important limitations of the study are the retrospective design and the independent choice of the surgeon for the technique to be used for harvesting. Thus, the bias of the surgeon cannot be ruled out. Another limitation is the long duration of the study causing missing patient data and exclusion of those patients.

\section{Conclusions}

In conclusion, saphenous harvest wound complications of CABG have a negative effect on the comfort and psychology of patients. There was a decrease in the incidence of postoperative wound complications and consequently a decrease in the duration of compression stocking use, owing to preoperative CDU evaluation of GSV and the above-knee incision method. Thus, we recommend preoperative CDU evaluation, the open surgery technique and above-knee GSV use to avoid the SVI complications in CABG operations.

\section{Conflict of interest disclosure}

There are no known conflicts of interest in the publication of this article. The manuscript was read and approved by all authors.

\section{Compliance with ethical standards}

The study was approved by the Haydarpasa Numune Training and Research Hospital clinical ethics committee (HNEAH-KAEK 2021/146-3374).

\section{References}

1. Allen K, Cheng D, Cohn W, Connolly M, Edgerton J, Falk V, Martin J, Ohtsuka T, Vitali R. Endoscopic Vascular Harvest in Coronary Artery Bypass Grafting Surgery: A Consensus Statement of the International Society of Minimally Invasive Cardiothoracic Surgery (ISMICS) 2005. Innovations (Phila). 2005 Winter;1(2):51-60. doi: 10.1097/01.gim.0000196315.32179.82

2. Black EA, Campbell RK, Channon KM, Ratnatunga C, Pillai R. Minimally invasive vein harvesting significantly reduces pain and wound morbidity. Eur $J$ Cardiothorac Surg. 2002 Sep;22(3):381-6. doi: 10.1016/s1010-7940(02)00296-8

3. Siddiqi MS. Saphenous vein harvest wound complications: risk factors, identification, prevention, and management. Chronic Wound Care Management and Research. 2016; 3:147-56. doi: 10.2147/CWCMR.S82601

4. DeLaria GA, Hunter JA, Goldin MD, Serry C, Javid H, Najafi H. Leg wound complications associated with coronary revascularization. J Thorac Cardiovasc Surg. 1981 Mar;81(3):403-7.

5. Bitondo JM, Daggett WM, Torchiana DF, Akins CW, Hilgenberg AD, Vlahakes GJ, Madsen JC, MacGillivray TE, Agnihotri AK. Endoscopic versus open saphenous vein harvest: a comparison of postoperative wound complications. Ann Thorac Surg. 2002 Feb;73(2):523-8. doi: 10.1016/s00034975(01)03334-3

6. Ferdinand FD, MacDonald JK, Balkhy HH, Bisleri G, Hwang HY, Northrup P, Trimlett RHJ, Wei L, Kiaii BB. Endoscopic Conduit Harvest in Coronary Artery Bypass Grafting Surgery: An ISMICS Systematic Review and Consensus Conference Statements. Innovations (Phila). 2017 Sep/Oct;12(5):301-319. doi: 10.1097/IMI.0000000000000410

7. Temizkan V, Ugur M, Arslan G, Alp I, Yedekci E, Ucak A, Yilmaz AT. Comparison of conventional technique and ultrasonographic mapping in saphenous 
vein harvesting. Heart Surg Forum. 2013 Oct; 16(5):E248-51. doi: 10.1532/HSF98.2013134

8. Perrault LP, Jeanmart H, Bilodeau L, et al. Early quantitative coronary angiography of saphenous vein grafts for coronary artery bypass grafting harvested by means of open versus endoscopic saphenectomy: a prospective randomized trial. Thoracic and Cardiovascular Surgery. 2004;127(5):1402-7. doi: 10.1016/j.jtcvs.2003.10.040

9. Greenfield GT, Whitworth WA, Tavares LL, Wittenbraker MT, Wallace DM, Valdivia JA, Campbell K, Williams L, Black E, Pillai R, Caskey MP, Bladergroen MR. Minimally invasive vein harvest and wound healing using the SaphLITE Retractor System.
Ann Thorac Surg. 2001 Sep;72(3):S1046-9. doi: 10.1016/s0003-4975(01)02944-7

10. Allen KB, Griffith GL, Heimansohn DA, Robison RJ, Matheny RG, Schier JJ, Fitzgerald EB, Shaar CJ. Endoscopic versus traditional saphenous vein harvesting: a prospective, randomized trial. Ann Thorac Surg. 1998;66(1):26-31. doi: 10.1016/s0003-4975(98)00392-0

11. Yilmaz AT, Ozal E, Barindik N, Günay C, Tatar H. The results of radial artery Y-graft for complete arterial revascularization. Eur J Cardiothorac Surg. 2002 May;21(5):794-9. doi: 10.1016/s1010-7940(02)00096-9

12. Ramasastry SS, Dick GO, Futrell JW. Anatomy of the saphenous nerve: relevance to saphenous vein stripping. Am Surg. 1987 May;53(5):274-7. 